\title{
As políticas federais e reconfigurações espaciais na Amazônia*
}

Maurílio de Abreu Monteiro - Professor do Núcleo de Altos Estudos Amazônicos, da Universidade Federal do Pará (NAEA-UFPA)

Maria Célia Nunes Coelho - Professora do Departamento de Geografia, da Universidade Federal do Rio de Janeiro (UFRJ)

\section{Resumo}

Neste artigo, analisam-se as repercussões sociais e espaciais das políticas federais dirigidas para a Amazônia oriental brasileira no século XX. Inicialmente são tratadas as tentativas de se restabelecer 0 dinamismo da produção gomífera. Em seguida, são abordados os desdobramentos das políticas do pósguerra. Analisam-se ainda as novas políticas federais para a região implantadas após o golpe militar de 1964. Também são examinadas as políticas federais adotadas com o fim dos governos militares. Concluise com a distribuição das políticas federais em dois grandes grupos, segundo seus fundamentos estratégicos: um baseado na eficácia da intervenção estatal nos processos de desenvolvimento e outro baseado na eficiência das forças do mercado.

\begin{abstract}
This paper analyzes the social and spatial repercussions of federal policies designed for the Brazilian Eastern Amazon region, in the $20^{\text {th }}$ century. Initially, the paper examines the attempts to re-establish, at a regional level, the dynamics of the rubber production. The new policies developed implemented after the military coup of 1964 and the new policies for the region, adopted after the military regime, as well as the new institutional approach are also analyzed. We conclude with the distribution of federal policies in two large groups, according to their strategy principles: one based on the efficiency of state intervention in the development processes, and another based in the efficiency of the market forces.
\end{abstract}

\section{Palavras-chave}

Amazônia, políticas federais, mudanças espaciais.

\section{Keywords}

Amazonia, federal policies, spatial changes.

* A elaboração deste artigo contou com o apoio do CNPq. 
Maur lio de Abreu Monteiro / Maria C lia Nunes Coelho

\section{1 - INTRODUÇÃ 0}

Buscar compreender os problemas contempor neos da Amaz nia requer que se faça uma incurs o, mesmo que breve, pelas pol ticas federais dirigidas, no s culo passado, para a regi o, pois estas pol ticas tiveram papel decisivo na modelagem das din micas sociais atualmente presentes em termos regionais.

Trata-se de uma incurs o que, necessariamente, remonta $s$ tentativas do governo central para restabelecer o dinamismo da produç o gom fera em termos regionais. Todavia, o marco mais relevante destas aç es federais encontra-se nos anos 40 do s culo passado, momento no qual se abriu um novo per odo do intervencionismo do Estado brasileiro na economia nacional e regional inaugurado pelo governo Vargas. A ruptura com a hist ria econ mica anterior foi dada pela adoç o de mecanismos de planejamento alimentados por uma ideologia de integraç o nacional, que teve como express o o que se chamou "Marcha para o Oeste".

Naquele contexto hist rico, em termos mundiais, ganhava força a id ia de que para um pa s desenvolver-se deveria, primeiramente, incorporar suas regi es economicamente menos desenvolvidas s regi es mais din micas. No caso do Brasil, esta nova etapa do reordenamento do territ rio nacional vinculou-se a aç es planejadas pelo governo federal. Assim, a vis o de fronteira ganhou novos significados, $\mathrm{n}$ o excludentes entre si: o de lugar de expans o do povoamento e fronteira de recursos, e de lugar a ser incorporado din mica da economia nacional.

No final da d cada de 1950, o movimento migrat rio que vinha sendo canalizado para as reas agr colas do Centro- $S$ ul e para o centro industrializado do pa s começou a ser redirecionado para o Norte do pa s. A id ia da Amaz nia como fronteira de povoamento e de expans o agr cola foi concretamente viabilizada pela pol tica de abertura de estradas. Conseq entemente, pela primeira vez na hist ria regional, as reas de terra firme superam o dinamismo e os ritmos de crescimento das reas ribeirinhas, que perderam a condiç o de eixos priorit rios da expans o econ mica regional. A partir de ent o as estrat gias adotadas pelo governo federal passaram a crescentemente ganhar formas concretas por meio da elaboraç o e implementaç o de planos de desenvolvimento regional, aos quais se articularam a criaç o de instituiç es, o estabelecimento de pol ticas p blicas, a implementaç o de mecanismos de financiamento, a edificaç o de obras de infraestrutura, etc (Quadro 1). 


\begin{tabular}{|c|c|c|c|c|c|c|c|}
\hline $\begin{array}{c}\text { Plano de defesa da } \\
\text { Borracha }\end{array}$ & $\begin{array}{l}\text { Batalha da } \\
\text { Borracha }\end{array}$ & Planos de metas & $\begin{array}{l}\text { Operação } \\
\text { Amazônia }\end{array}$ & $\begin{array}{l}\text { I PND } \\
\text { PIN } \\
\text { I PDA }\end{array}$ & $\begin{array}{c}\text { II PND } \\
\text { POLAMAZÔNIA }\end{array}$ & \begin{tabular}{|c|} 
II PND \\
PGC \\
Calha Norte
\end{tabular} & $\begin{array}{l}\text { Brasil em Ação } \\
\text { Avança Brasil }\end{array}$ \\
\hline $1912-1914$ & $1942-1947$ & 1956-1961 & $1966-1970$ & $\begin{array}{c}1969-1974 \\
1971 \\
1971\end{array}$ & 1974-1979 & $\begin{array}{c}1975-1979 \\
1980-1989 \\
1985-\ldots\end{array}$ & $\begin{array}{l}1996-1999 \\
2000-2003\end{array}$ \\
\hline \multirow[t]{2}{*}{$\begin{array}{l}\text { Destinação de } \\
\text { recursos pelo governo } \\
\text { federal; } \\
\text { criação da } \\
\text { Superintendência para } \\
\text { a Defesa da Borracha; } \\
\text { redução das alíquotas } \\
\text { dos impostos cobrados } \\
\text { sobre a borracha. }\end{array}$} & $\begin{array}{l}\text { Criação no ano } \\
\text { de } 1941 \text { do } \\
\text { Serviço Especial } \\
\text { de Mobilização } \\
\text { de Trabalhadores } \\
\text { (SEMTA) e da } \\
\text { Comissão } \\
\text { Administrativa } \\
\text { do } \\
\text { Encaminhamento } \\
\text { de Trabalhadores } \\
\text { para a Amazônia } \\
\text { (CAETA). }\end{array}$ & $\begin{array}{l}\text { Criação da } \\
\text { Superintendência } \\
\text { do Plano de } \\
\text { Valorização } \\
\text { Econômica da } \\
\text { Amazônia } \\
\text { (SPVEA), que } \\
\text { elaborou o } 1^{\circ} \\
\text { Plano de } \\
\text { Desenvolvimento } \\
\text { da Amazônia, em } \\
1955 \text {. }\end{array}$ & $\begin{array}{l}\text { Definição de } \\
\text { políticas de } \\
\text { incentivos fiscais } \\
\text { aplicados a } \\
\text { projetos } \\
\text { agropecuários, } \\
\text { indústrias e de } \\
\text { serviços básicos. } \\
\text { Criação da } \\
\text { o Superintendência } \\
\text { da Zona Franca de } \\
\text { Manaus } \\
\text { (SUFRAMA), do } \\
\text { BASA e da } \\
\text { SUDAM. }\end{array}$ & $\begin{array}{l}\text { Recursos } \\
\text { destinados à } \\
\text { redistribuição de } \\
\text { terras - } \\
\text { PROTERRA }\end{array}$ & $\begin{array}{l}\text { Incentivos fiscais e } \\
\text { creditícios }\end{array}$ & & \\
\hline & & $\begin{array}{l}\text { Rodovia Belém- } \\
\text { Brasília }\end{array}$ & & $\begin{array}{l}\text { Construção das } \\
\text { rodovias: } \\
\text { Transamazônica, } \\
\text { Cuiabá- } \\
\text { Santarém, } \\
\text { Manaus-Porto } \\
\text { Velho. }\end{array}$ & $\begin{array}{l}\text { Usina Hidrelétrica } \\
\text { de Tucuruí }\end{array}$ & & $\begin{array}{l}\text { Eixo do Arco Norte } \\
\text { (subarco ocidental e } \\
\text { subarco oriental); } \\
\text { Eixo Madeira- } \\
\text { Amazonas; } \\
\text { Eixo Araguaia- } \\
\text { Tocantins }\end{array}$ \\
\hline
\end{tabular}


Maur lio de Abreu Monteiro / Maria C lia Nunes Coelho

As estrat gias de modernizaç o regional patrocinadas pelo governo federal na Amaz nia ganharam novas feiç es no per odo que se seguiu ao golpe militar de 1964 . 0 Estado nacional, comandado pelos militares, beneficiando-se, no in cio dos anos 70 , do dinheiro farto e barato origin rio dos pa ses produtores de petr leo, assumiu uma faceta desenvolvimentista, isto, provedor das infra-estruturas b sicas necess rias preparaç o do espaço para os investidores a serem atra dos, al $\mathrm{m}$ de participar diretamente em diversas atividades econ micas. Todavia, a crise do petr leo, no in cio da d cada de 1970 , a elevaç o das taxas de juros e o agravamento da d vida externa brasileira na segunda metade da d cada de 1980 alteraram significativamente as bases sobre as quais se assentava a capacidade de intervenç o federal na regi 0 .

Com o processo de abertura pol tica (1985), houve crescente processo de descentralizaç o administrativa. A despeito da crise fiscal e da reduç o da capacidade de investimentos, o Estado Nacional ainda ocupava papel de destaque nos discursos em relaç o ao desenvolvimento regional. A onda de descentralizaç o administrativa afirmou-se com a promulgaç o da Constituiç o de 1988 e com as tentativas de realizaç o de reformas do Estado.

As id ias que se consolidaram, em termos mundiais, nos anos 80 , de cunho nitidamente neoliberais e que criticavam a necessidade da intervenç o estatal para favorecer o desenvolvimento, $s$ ganharam força no Brasil nos anos 90, per odo no qual houve uma mudança significativa nos discursos e nas pr ticas do Estado sobre as formas de se alcançar o almejado desenvolvimento do pa s e de suas regi es. 0 mercado passou a ser ungido como ente principal capaz de viabilizar processos de desenvolvimento regional.

Nos anos 90, o Estado, carente de poupança e de acessos $\mathrm{f}$ ceis ao capital, recuou sua capacidade de provedor do desenvolvimento e acomodou-se s exig ncias do Banco Mundial e do Fundo Monet rio Internacional de aumentar as exportaç es. Seguindo um modelo de reduç o do custo de transporte com a finalidade de aumentar a competitividade dos produtos brasileiros, e em funç o do quadro nacional e internacional de crise financeira, iniciou-se no governo do Presidente Fernando Henrique Cardoso aç es voltadas ao est mulo de desenvolvimento dos eixos de integraç o, buscando interligar reas de produç o ao mercado internacional, 1 gicas que foram mantidas no governo do Presidente Lula da Silva, e caso venham a ser concretizados, poder o desenhar uma nova trajet ria hist rica para a A maz nia e para o estado do Par . 
Considerando as transformaç es ocorridas na regi o e no estado do Par, parece imprescind vel o exame das pol ticas governamentais para se entender as mudanças nos processos sociais, econ micos, espaciais e culturais que marcaram a fronteira amaz nica durante grande parte do s culo XX. 0 exame cr tico de um per odo que se inicia na d cada de 1940 e que $n$ o se completa ao fim do s culo XX representa, portanto, uma tentativa de entendimento de como a regi o amaz nica foi sendo recriada ou reinventada e que pol ticas contribu ram para o seu dr stico processo de transformaç o que tem levado devastaç o de parte de sua floresta, expans o demogr fica, s mudanças culturais e s lutas dos ind genas, trabalhadores rurais e urbanos, agricultores familiares, sem-terra e quilombolas. A estas intervenç es patrocinadas pelo governo federal e que tiveram influ ncia decisiva na construç o da hist ria recente da regi o e do estado do Par que se d nfase neste artigo.

\section{2 - AS TENTATIVAS PARA RESTABELECER 0 DINAMISMO DA PRODUÇÃO G OMÍFERA}

0 per odo de prosperidade da economia da borracha na A maz nia, iniciado na segunda metade do s culo XIX, foi interrompido em 1912 pela dr stica reduç o dos seus preços decorrente da crescente produç o da borracha oriunda das plantaç es de seringueiras na Ásia. Os " anos dourados" da economia da borracha na A maz nia ficaram basicamente restritos ao per odo de 1880 a 1912 no qual o impacto econ mico e demogr fico, com destaque para a expans o comercial, para o crescimento populacional e para a conseq ente urbanizaç o de algumas reas da regi o (Weinstein, 1993). Segundo Machado (1997, p. 22), o boom da borracha modificou as condiç es locais de tal forma que, pela primeira vez, o termo A maz nia foi empregado para designar o extremo Norte.

No contexto hist rico de decl nio da produç o registrou-se uma t mida tentativa de planejamento federal da economia regional implementada pelo governo federal. Em 1912 , no momento de crise da economia regional, a Uni o criou o "Plano de Defesa da Borracha”, para o qual o governo destinou recursos espec ficos e criou a Superintend ncia para a Defesa da Borracha, para coordenar sua aplicaç o. 0 plano envolvia tanto aç es voltadas diretamente para a manutenç o da produç o regional de borracha quanto para a melhoria das condiç es sociais da regi o. Como parte do plano, o governo federal previa a concess o de remuneraç o aos que efetivassem a implantaç o de 
seringais ou instalaç es para o beneficiamento do 1 tex. Passou tamb $\mathrm{m}$ a oferecer bonificaç es em dinheiro a quem edificasse instalaç es portu rias e estradas de ferro, dentre outras obras. Al m disso, o governo reduziu as al quotas dos impostos cobrados sobre a borracha, sob a alegaç o de torn - la mais competitiva no mercado internacional.

Essa experi ncia teve duraç o muito limitada. J em 1914 , o governo federal n o mais destinou recursos para tais aç es. 0 "Plano de Defesa da Borracha” foi ent o finalizado sem cumprir seus objetivos. Com o colapso da produç o gom fera, a regi o viveu um per odo de retraç o de suas exportaç es.

No per odo marcado pelo dinamismo da economia da borracha, a regi o Norte contou com um alto crescimento populacional, passando de 332.847 habitantes, em 1872, a 1.439.052, em 1920 ( $\mathrm{Gr}$ fico 1 ). Para esta poca, se calculou que mais de 300.000 nordestinos, sobretudo cearenses, foram atra dos pelo crescimento da economia da borracha na regi o Norte. As correntes migrat rias nordestinas dirigiram-se

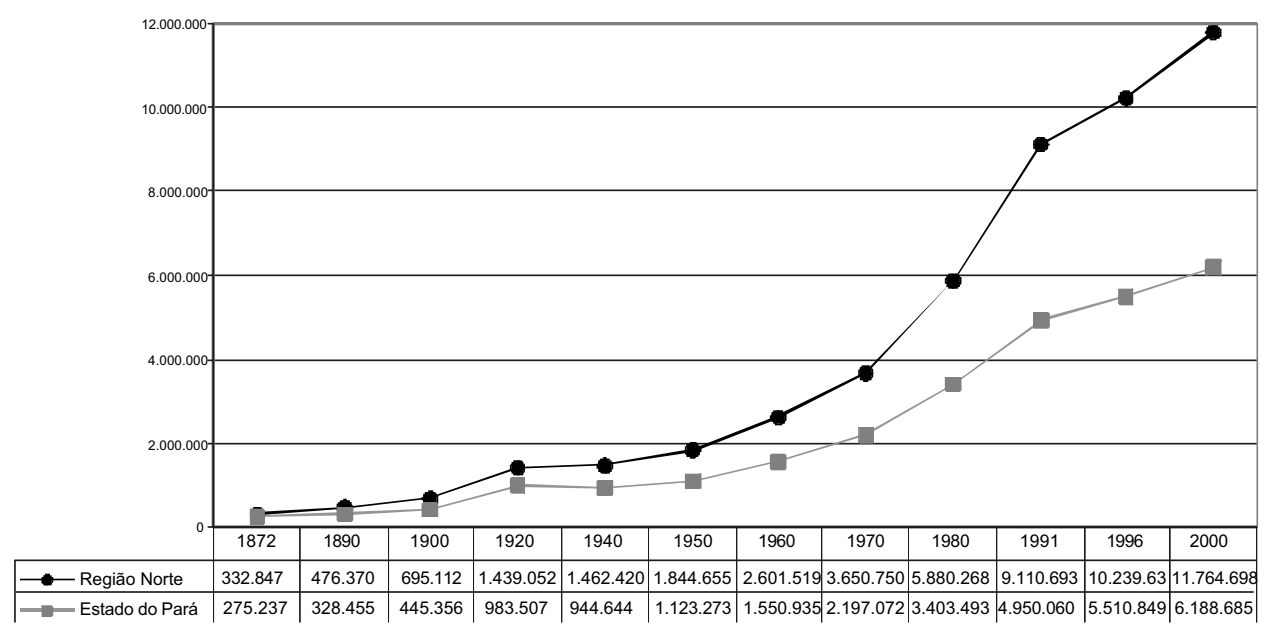

particularmente para os vales do Juru , Purus, Madeira, Tapaj s e Xingu. Gr fico 1: Evoluç o da populaç o da regi o Norte (exclusive Tocantins) e do Estado do Par (1 872 a 2000)

Fonte: Censos demogr ficos IBGE.

Com a dr stica reduç o da produç o nos seringais, a regi o viveu uma estagnaç o do seu crescimento demogr fico, apresentando, em 1940, um total populacional da ordem de 1.462.420 (G r fico 1). 0 Par e o Acre tiveram reduç o populacional, sendo que este sofreu uma perda de $13,6 \%$.

96 
Foi neste contexto hist rico que, por volta de 1927, Henry Ford, famoso capitalista norte- americano, recebeu do governo brasileiro terras ao sul de Santar m, s margens do rio Tapaj s, que ficaram conhecidas como Fordl ndia, com a intenç o de produzir borracha natural, utilizando para isto o sistema de plantation. Em 1934, a empresa tinha mudado para uma rea mais favor vel agricultura em Belterra. A Company of Brazil tinha 2.723 empregados em 1941. Em 1945, constatado o fracasso do plantio, Fordl ndia e Belterra foram repassados ao governo brasileiro.

As aç es de intervenç o federal na regi os foram retomadas nos meados da d cada de 1940, em decorr ncia de desdobramentos da Segunda G uerra Mundial em relaç o ao mercado mundial da borracha. Os japoneses, em 1942, passaram a controlar $97 \%$ das reas produtoras de borracha na Ásia e somente a ind stria americana precisava de mat ria-prima para produzir 30 milh es de pneus por ano (Corr a, 1967 , p. 23). Diante deste quadro, os Estados Unidos desenvolveram programas para garantir o abastecimento de sua ind stria com borracha.

Naquele contexto foram assinados, em 1942, os "Acordos de Washington”, por meio dos quais, ficou pactuado o compromisso de o Brasil suprir as forças aliadas de diversas mat rias- primas, dentre as quais a borracha. A partir de ent o foram adotadas diversas medidas para elevar a sua produç o na A maz nia, que ficaram conhecidas como a "Batalha da Borracha".

Em 1941, a produç o de borracha na A maz nia atingiu pouco mais de 18 mil toneladas por ano, e ocupava, aproximadamente, $34 \mathrm{mil}$ pessoas na extraç o do 1 tex. Para aumentar a produç o para 45 mil toneladas, era necess rio que fosse, pelo menos, duplicado o $\mathrm{n}$ mero de trabalhadores envolvidos naquela atividade (CORREA, 1967, p. 89). Para tanto, foram criados o Serviço Especial de Mobilizaç o de Trabalhadores (SEMTA) e a Comiss o Administrativa do Encaminhamento de Trabalhadores para a Amaz nia (CAETA), que mobilizaram para os seringais $48 \mathrm{mil}$ pessoas, principalmente nordestinos (FERREIRA FILHO, 1965). Al $\mathrm{m}$ da SEMTA e da CAETA, para garantir o transporte dos trabalhadores, da borracha e de suprimentos, o governo criou o Serviço de Navegaç o da Amaz nia e Administraç o do Porto do Par (SNAPP).

A "Batalha da Borracha" durou at 1947 e seus resultados foram bem modestos. De 1941 a 1945 , a produç o anual de borracha natural subiu apenas 10.000 toneladas (FERREIRA FILHO, 1965, p. 277) e seus impactos sobre as din micas sociais ent o existentes no Par foram pouco relevantes.

Merece nota o fato de que as aç es federais em torno da "Batalha 
Maur lio de Abreu Monteiro / Maria C lia Nunes Coelho

da Borracha" iniciaram-se ainda em um cen rio no qual o Acre (uma porç o de terra rica em borracha comprada da Bol via por meio de uma negociaç o que deu origem ao Tratado de Petr polis de 1903) j fazia parte do territ rio brasileiro. Em 1943, o Acre foi desmembrado do Amazonas e o Amap , do Par , com a criaç o do Territ rio Federal do Acre e do Territ rio Federal do Amap .

De modo geral, os pequenos centros comerciais e populacionais, concentrados nos eixos formados pelos rios, enfraquecidos pelo decl nio do com rcio da borracha e marcados pelos esforços nem sempre bemsucedidos de diversificaç o da produç o, continuavam a perder populaç o. A retomada do crescimento populacional na regi o, verificada entre 1940 e 1950 ( $\mathrm{r}$ r fico 2), se deveu a movimento migrat rio subseq ente ao recrudescimento da exploraç o da borracha natural em decorr ncia da "Batalha da Borracha" e da formaç o de um mercado interno da borracha, com o desenvolvimento da ind stria paulista (IBGE,

\begin{tabular}{|c|c|c|c|c|c|c|c|c|}
\hline \multicolumn{9}{|l|}{$\left.\begin{array}{l}6.500 .000 \\
6.000 .000\end{array}\right]$} \\
\hline \multicolumn{9}{|l|}{5.500 .000} \\
\hline \multicolumn{9}{|l|}{5.000 .000} \\
\hline \multicolumn{9}{|l|}{4.500 .000} \\
\hline \multicolumn{9}{|l|}{3.500 .000} \\
\hline \multicolumn{2}{|l|}{3.000 .000} & \multicolumn{7}{|c|}{2.500 .000} \\
\hline \multicolumn{9}{|l|}{2.000 .000} \\
\hline \multicolumn{9}{|l|}{$1.000 .000-$} \\
\hline \\
\hline & 1940 & 1950 & 1960 & 1970 & 1980 & 1991 & 1996 & 2000 \\
\hline —-Pará & 944.644 & 1.123 .273 & 1.529 .293 & 2.167 .018 & 3.403 .391 & 4.950 .060 & 5.510 .849 & 6.188 .685 \\
\hline -Amazonas & 438.008 & 514.099 & 708.459 & 955.235 & 1.430 .089 & 2.103 .243 & 2.389 .279 & 2.840 .889 \\
\hline$\smile$ Rondônia & 0 & 36.935 & 69.792 & 111.064 & 491.069 & 1.132 .692 & 1.229 .306 & 1.377 .792 \\
\hline$\rightarrow$-Acre & 79.768 & 114.755 & 158.184 & 215.299 & 301.303 & 417.718 & 483.593 & 557.337 \\
\hline ——Amapá & 0 & 37.477 & 67.750 & 114.359 & 175.257 & 289.397 & 379.459 & 475.843 \\
\hline - Roraima & 0 & 18.116 & 28.304 & 40.885 & 79.159 & 217.583 & 247.131 & 324.152 \\
\hline
\end{tabular}

Gr fico 2: Evoluç o da populaç o dos estados da regi o Norte (exclusive Tocantins) 1940 a 2000)

Fonte: Censos demogr ficos IBGE.

D essa forma, a "Batalha da Borracha", como pol tica federal para a Amaz nia, $\mathrm{n}$ o alterou a organizaç o do espaço regional, que tinha como uma das caracter sticas principais o papel fundamental desempenhado pelos rios como nicas vias de transporte intra-regional. Isto produzia implicaç es diretas na distribuiç o da populaç o das 
cidades e vilas e na organizaç o da circulaç o de mercadorias. At a d cada de 1940, no Par, as nicas vias de transporte, que $\mathrm{n}$ o as fluviais ou a mar tima, consistiam de duas ferrovias (uma que ligava Bel $\mathrm{m}$ a Bragança e outra, a do Tocantins, que conectava Tucuru a Jotobal) (Figura 1) e uma rodovia que interligava Bel $\mathrm{m}$ a Santa Izabel. As outras poucas estradas existentes encontravam-se em "estado precar ssimo" (Mendes, 1971, p.33). Esta situaç o foi alterada significativamente a partir da implementaç o de aç es federais nas $\mathrm{d}$ cadas seguintes, iniciadas com a edificaç o da nova capital federal no planalto central brasileiro e com a construç o da rodovia Bel mBras lia (Figura 1).

\section{3 - A CRIAÇÃO DA SPVEA E A CONSTRUÇÃO DA BELÉM- BRA SÍLIA}

0 cen rio mundial $\mathrm{p}$ s-guerra e a reconstruç o da Europa sob a gide do Plano Marshall contribu ram para que houvesse alteraç o nas formulaç es te ricas acerca do papel dos Estados nacionais nos processos de desenvolvimento dos pa ses latino-americanos. Passou a ser predominante a id ia de que a intervenç o do Estado na economia $\mathrm{n}$ o era somente ben fica, mas necess ria para o desenvolvimento econ mico. Tratou-se da afirmaç o de uma vis o sobre o papel do Estado nos processos de desenvolvimento que se contrapunha a um conjunto de id ias que defendia o mercado como o melhor instrumento para dirigir a alocaç o dos recursos com vistas promoç o do desenvolvimento de diferentes regi es e naç es. De forma que as d cadas que sucederam a Segunda Guerra Mundial foram marcadas, em termos gerais, pelo relativo otimismo em relaç o $\mathrm{s}$ possibilidades de generalizaç o do desenvolvimento e necessidade da participaç o do Estado nacional nestes processos. Ganhou tamb m impulso o pressuposto da efic cia do planejamento do desenvolvimento, que poderia ser alcançado por meio de uma racionalizaç o da aplicaç o de capitais, sob a coordenaç o estatal.

$\mathrm{S}$ o id ias que $\mathrm{v}$ o influenciar diretamente a formulaç o e a implementaç o de tentativas estrat gicas de modernizaç o patrocinadas pelo Estado nacional para a Amaz nia. A força dessas convicç es contribuiu para que, com base na Constituiç o de 1946, se estabelecesse um programa de desenvolvimento para a A maz nia, que seria financiado por uma parcela de $3 \%$ do total da receita de impostos federais, durante um prazo de vinte anos consecutivos. Al m disso, os governos estaduais e municipais da regi o deveriam contribuir com parcela id ntica de suas 
receitas. 0 plano de desenvolvimento da Amaz nia s entrou em vigor seis anos mais tarde, com a aprovaç o da lei que o regulamentava, em 1953. Para a execuç o do plano, o Congresso criou um rg o coordenador denominado Superintend ncia do Plano de Valorizaç o Econ mica da Amaz

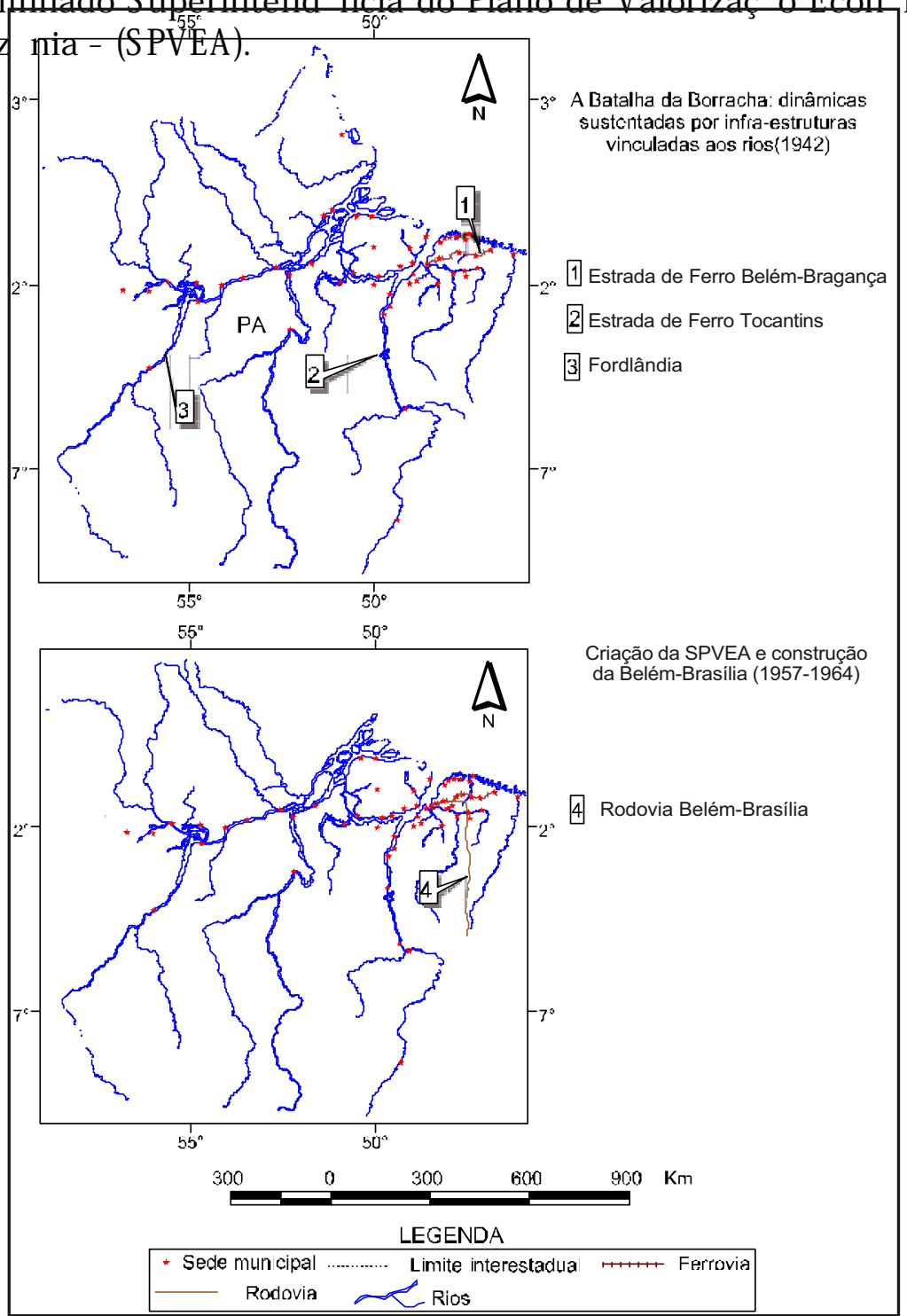

Figura 1: Elementos da reconfiguraç o espacial na Amaz nia oriental (1900 - 1964). 
Fontes: BRASIL (1 973); Ferreira Filho (1 965); IBGE (1 984); IRDA; IBGE (1 966); MARANHÃO (2000); Martinelo (1 985); Mendes (1 971); SUDAM (1 976); Valverde e Dias (1967); A map (2000).

Em 1955, foi estabelecido o primeiro Plano de Desenvolvimento da Amaz nia, sob a responsabilidade gerencial da spveA. A regi o politicamente definida como rea de jurisdiç o da SPVEA, que ia al $\mathrm{m}$ da regi o Norte do IBGE ou "Amaz nia Cl ssica", ficou conhecida como "A maz nia Legal". A nova regi o recobria cerca de $60 \%$ do territ rio brasileiro. 0 Plano de Desenvolvimento da Amaz nia tratava, basicamente, da indicaç o da necessidade de realizaç o de diversas obras p blicas. A principal obra era a rodovia Bel m-Bras lia, que estabeleceria a primeira ligaç o terrestre permanente entre o Par e o Centro-Sul do pas.

A construç o da rodovia Bel $\mathrm{m}$ - Bras lia era uma das obras estabelecidas no "Plano de Metas" (1 956-1961) do G overno do Presidente Juscelino Kubitschek, que tinha como objetivo a construç o de Bras lia. Esta era uma decis o que se articulava com id ias presentes bastante influentes no mundo naquela poca e que indicavam que qualquer naç o para se desenvolver teria que necessariamente integrar seus mercados internos (Myrdal, 1968). A rodovia Bel m-Bras lia, seguindo o sentido norte- sul, teria este papel de integraç o dos mercados do Centro-Sul do pa s com a Amaz nia oriental brasileira (Figura 1).

A construç o desta rodovia ficou a cargo da RODOBRÁs, que estava diretamente subordinada SPVEA. Em 31 de janeiro de 1960, a "Caravana de integraç o nacional- coluna norte" completou o trajeto entre Bel m e Bras lia, um percurso de 2.162 quil metros que naquela poca foi efetuado em uma semana, pois se tratava ainda de uma estrada n o pavimentada (BRASIL, 1960, p. 23).

De 1950 a 1960 , o crescimento populacional foi mais elevado nos territ rios rec $\mathrm{m}$-criados ( $\mathrm{r}$ fico 2), com grande destaque, para o territ rio do Amap, onde se implantava a mineraç o do mangan $\mathrm{s}$, a mais antiga mineraç o de grande escala na Amaz nia. No per odo de 1960 a 1970, graças construç o da rodovia Bel m-Bras lia, crescia tamb m o norte do estado de $G$ oi s e o sudoeste do Maranh o.

Al $\mathrm{m}$ da Bel m-Bras lia, as rodovias constru das na $\mathrm{d}$ cada de 1970 tiveram grande import ncia na reestruturaç o espacial dos estados do Par , Mato G rosso e Rond nia, impulsionando, portanto, mudanças territoriais, econ micas, sociais e ambientais (Figura 2). As alteraç es 


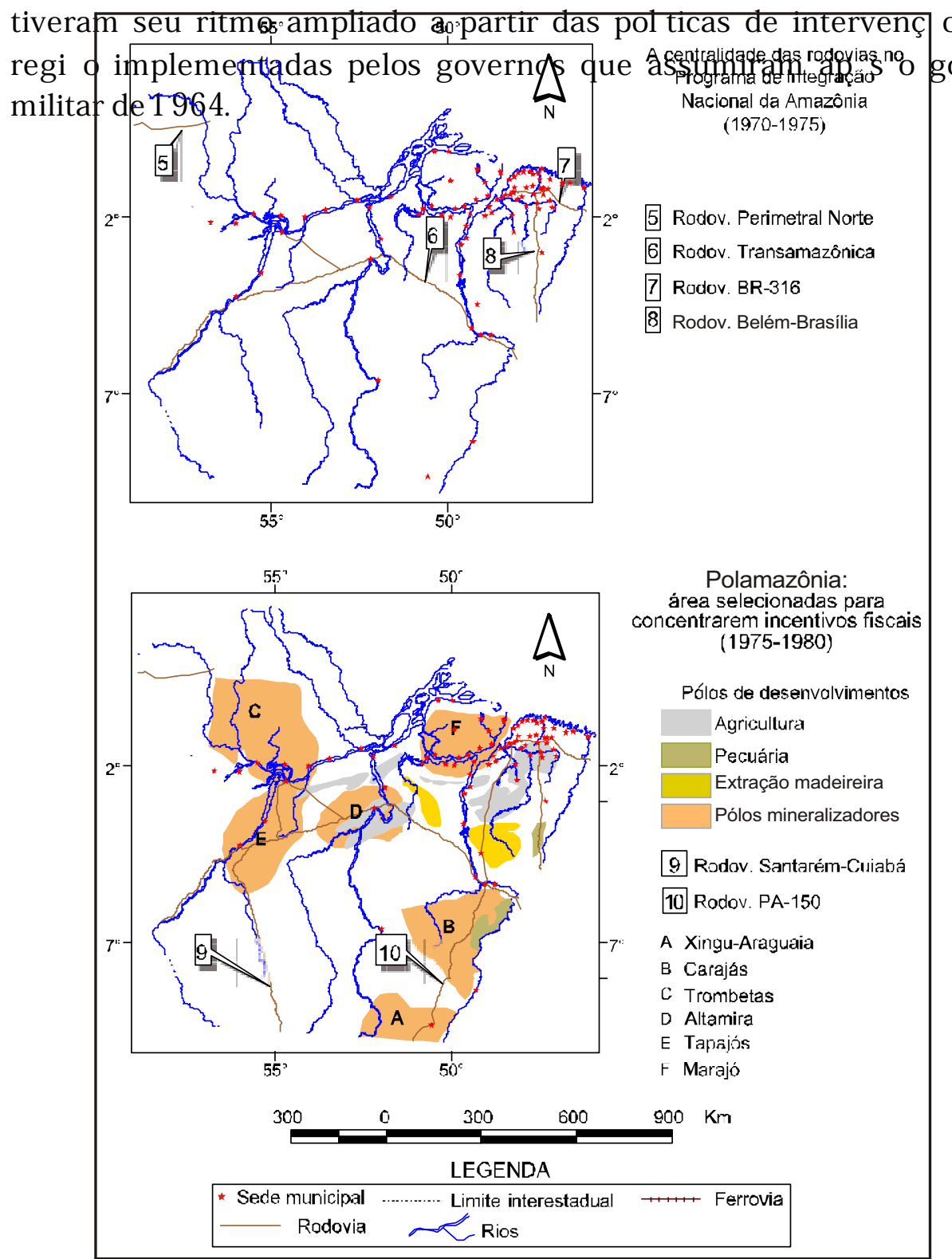

Figura 2: Elementos da reconfiguraç o espacial na Amaz nia oriental (1970 - 1980).

Fontes: BRASIL (1 973); Ferreira Filho (1 965); IBGE (1 984); IRDA; IBGE (1 966); MARANHÃO (2000); Martinelo (1 985); Mendes (1 971); SUDAM (1 976); Valverde e Dias (1967); Amap (2000). 


\section{4 - A "OPERAÇÃ O AMAZÔNIA"}

As pol ticas implementadas a partir do golpe militar de 1964 constitu ram-se um marco hist rico em termos da ampliaç o da import ncia exercida pelas pol ticas federais sobre mudanças na organizaç o social e econ mica do Par. Na coaliz o de forças que tomou o poder no Brasil com o golpe de 1964, eram os militares que tinham a principal motivaç o para agir sobre a Amaz nia. As empresas nacionais e as empresas multinacionais tinham outras alternativas de investimento, bem mais atraentes, fora da regi o amaz nica. Desta forma, o estado autorit rio, a partir da converg ncia da geopol tica com a doutrina de segurança nacional, formulou uma doutrina de intervenç o interna, que tomou formas espec ficas no caso da Amaz nia (OLIVEIRA, 1994, p. 86).

De tal maneira que foram os interesses de natureza estrat gica e militar, combinados entre si, elementos relevantes para a elaboraç o, pelo grupo militar, de pol ticas de intervenç o na regi o. As preocupaç es com o inimigo interno e com a cobiça internacional unificavam os principais setores militares em relaç o necessidade e forma de ocupaç o da Amaz nia. Os militares empenharam-se, ent o, no desenvolvimento de pol ticas que viabilizassem a integraç o econ mica da regi o ao restante do pa s e na defesa das reas fronteiriças.

Com base numa avaliaç o de que din micas decorrentes da estruturaç o da sociedade local eram respons veis pelo atraso da economia regional e, ao mesmo tempo, que os atores locais seriam incapazes de se converterem em elementos propulsores de processos de desenvolvimento regional, os governos militares decidiram "ocupar" a A maz nia, atraindo para a regi o o empresariado "inovador" do CentroSul ou mesmo do exterior. Estabeleceu-se, assim, um "modelo de desenvolvimento amaz nico", sob a responsabilidade de um Estado que desempenhou o papel de promotor/indutor do crescimento econ mico, promovendo a industrializaç o espacialmente concentrada em alguns pontos da Amaz nia, particularmente do Par. Ao induzir a expans o capitalista, o Estado nacional promoveu alteraç es nas din micas sociais presentes no Estado e na regi o.

$\mathrm{J}$ nos primeiros anos dos governos militares, a intervenç o foi implementada a partir de um grande aparato institucional voltado consecuç o de aç es do Estado nacional para a regi o, medidas que em 
seu conjunto ficaram conhecidas como "O peraç o A maz nia”. Em 1953 , a SPVEA e o Banco de $\mathrm{Cr}$ dito da Amaz nia foram substitu dos pela Superintend ncia do Desenvolvimento da Amaz nia (SUDAM) e pelo Banco da Amaz nia S.A (BASA). A Zona Franca de Manaus SUFRAMA, que consistia de um projeto capitalista destinado a criar um centro de montagem e comercializaç o de produtos eletr nicos na A maz nia 0 cidental, foi criada em 1967. Neste contexto, inseremse o I Plano Q inq enal de Desenvolvimento para o per odo de 1967 a 1971 e o Plano Diretor de 1968. Neles o governo federal preconizava, basicamente, que caberia ao setor $\mathrm{p}$ blico a tarefa de atrair capitais para a regi o, o que seria feito por meio do fornecimento da infra- estrutura, da concess o da isenç o fiscal e de est mulos credit cios necess rios implantaç o dos empreendimentos capitalistas na regi 0 .

Estabeleceu-se, assim, uma pol tica de desenvolvimento regional semelhante que vinha sendo aplicada no Nordeste, especialmente no que se refere pol tica de incentivos fiscais. Pol tica que resultou na facilidade de apropriaç o de terras por grandes empresas e por fazendeiros e em mudanças significativas nas reas rurais, havendo a disseminaç o de grandes fazendas destinadas criaç o de gado bovino, em especial no sul e no sudeste do Par. Processos de apropriaç o fundi ria no geral vinculados disseminaç o de pastagens e que teve repercuss es nas din micas sociais e ecol gicas da regi o, acelerando a substituiç o das florestas e a ampliaç o da concentraç o fundi ria no estado do Par (Quadro 2).

As preocupaç es com a necessidade de superaç o do "atraso" da regi o e com sua ocupaç o produziram desdobramentos diversos, como a criaç o, no governo do general Castelo Branco, do projeto Jari, no munic pio de Almeirim (PA) em 1967, pelo milion rio norte- americano Daniel K. Ludwig. Tratava-se da implantaç o, na rea correspondente aos atuais munic pios de Almeirim (PA), Laranjal do Jari (AP) e Vit ria do Jari (AP), de megaprojetos, numa rea de 1,6 milh o de hectares, que envolviam a silvicultura para o abastecimento de uma f brica de celulose, o plantio de arroz, a implantaç o de projetos de extraç o mineral, dentre outros.

A noç o de que o grande capital seria o meio nico capaz de efetivamente implementar processo de modernizaç o na regi o foi um dos pontos principais das estrat gias de desenvolvimento dos governos 
militares. Foi assim o per odo marcado pela utilizaç o da pol tica de incentivos fiscais pelo Estado nacional para atrair e favorecer a implantaç o de grandes capitais na regi o.

\section{5 - 0 PROgRama De INTEgRAÇã 0 NACIONAL - PIN, A TRANSAMAZONNICA E OUTRAS NOVAS ESTRADAS}

Nos anos 70, tamb $\mathrm{m}$ foram implementadas aç es por parte do governo federal decorrentes de press es sociais no Nordeste (Oliveira, 1972: 114 ). Em 1971, o governo do G eneral M dici lançou o Programa de Integraç o Nacional - PIN que se articulava com o Programa de Redistribuiç o de Terras - PROTERRA.

Naquele mesmo ano, foi divulgado o Plano de Desenvolvimento da Amaz nia - PDA (SUDAM, 1971), um desdobramento do Plano Nacional de Desenvolvimento (Brasil, 1971), reprisava algumas diretrizes do PIN no que se refere necessidade da integraç o e da complementaridade das economias da Amaz nia e do Nordeste, e da indicaç o da prem ncia da utilizaç o agr cola racional da Amaz nia e da produç o para o mercado externo como uma via de desenvolvimento. Neste mesmo ano, para facilitar a ocupaç o da Amaz nia, o governo militar determinou que as faixas de $100 \mathrm{~km}$ de cada lado de todas as rodovias federais na Amaz nia brasileira passariam para a jurisdiç o do Instituto Nacional de Colonizaç o e Reforma Agr ria (INCRA).

0 Plano de Desenvolvimento da A maz nia para o per odo de 1972 1974 anunciava que as conquistas essenciais, quanto Amaz nia, propostas pelo governo federal, referiam-se utilizaç o de uma "estrat gia que promova o progresso de novas reas e a ocupaç o de espaços vazios" e "integraç o do desenvolvimento do Nordeste com a estrat gia da ocupaç o econ mica da Amaz nia” (SUDAM, 1971:13).

Esta integraç o com o desenvolvimento do Nordeste, preconizada pelo PDA, implicou, dentre outras aç es federais na regi o, a construç o da rodovia Transamaz nica e a implantaç o de $n$ cleos de colonizaç o ao longo do seu traçado. Esta rodovia e demais aç es do governo federal impulsionaram mudanças na demografia ( $\mathrm{Gr}$ fico 2 ); na economia, no padr o de ocupaç o territorial do Par (Figura 2), ao promover a ocupaç o da terra firme; e na estrutura fundi ria do agr rio regional (Quadro 2). Enfim na evoluç o do antropismo na Amaz nia (Fig 3 e 4).

A abordagem do planejamento do desenvolvimento regional apoiava-se na id ia da A maz nia como uma fronteira de povoamento e articulava- se com a vis o de "fronteira de recursos" (Mahar, 1978: 30). 
Um dos recursos existentes nesta fronteira era a terra, que abria a possibilidade de absorver contingentes de trabalhadores de diversas regi es do pa s. Particularmente, a met fora de Amaz nia como fronteira de povoamento foi expressa pelo slogan "Homem sem terra para uma torra com homonc" Nacto nor ndo ne onvarnoc militarac natroninaram

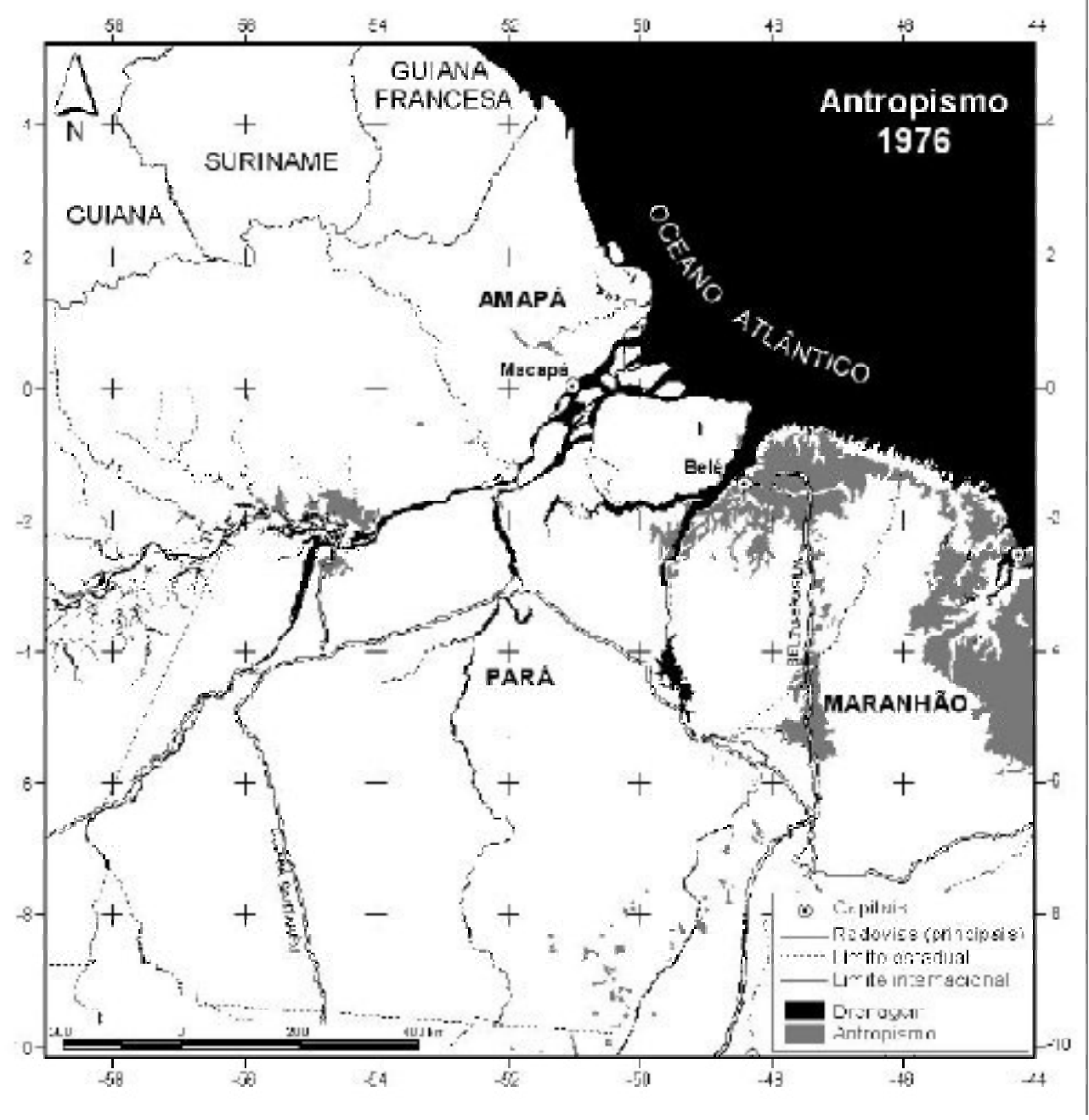

Figura 3: Evoluç o do antropismo na A maz nia, cobertura fitogeogr fica (1 976).

Fonte: IBGE, 2002. 


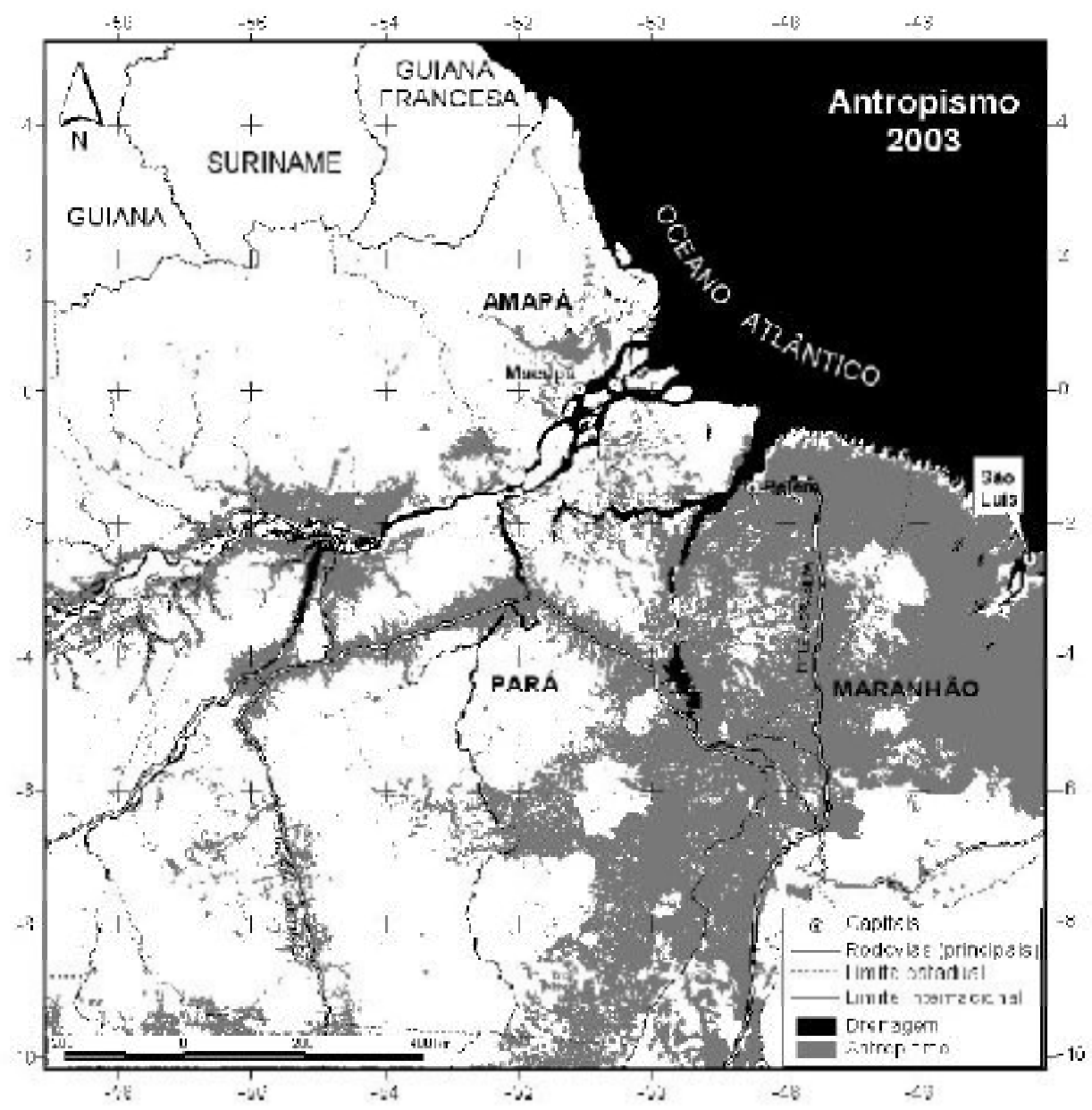

Figura 4: Evoluç o do antropismo na A maz nia, cobertura fitogeogr fica (1991).

Fonte: IBGE, 2002.

\section{6 - POLAMAZÔNIA: O ABANDONO DA COLONIZAÇÃO DIRIG I- DA E A OPÇÃO PELA CONCRETIZAÇÃO DOS GRANDES IN- VESTIMENTOS}

Na metade da d cada de 1970 , os mecanismos sobre os quais se apoiava o modelo de desenvolvimento de base industrial nacionalmente integrado, implantado pelos militares, apresentam sinais de esgota- 
mento e de incapacidade para manter acelerado o ritmo de crescimento econ mico. Neste per odo foi apresentado o II Plano Nacional de Desenvolvimento (II PND) (SUD AM, 1976), no qual se delinearam aç es estatais na tentativa de manter elevadas as taxas de crescimento econ mico. 0 governo federal, ent o, dirigiu suas aç es para dinamizar ou implantar no Brasil novos setores industriais produtores de bens de capital, iniciativas que pretendiam manter aquecida toda a economia nacional para o que, evidentemente, contribuiria a criaç o de novos espaços de investimentos. Para a geraç o de recursos visando consecuç o desta empreitada, desenvolveram-se aç es estatais, algumas das quais, direcionadas ao fomento e criaç o de projetos no estado do Par . Estes projetos deveriam entrar em funcionamento com relativa rapidez e produzir em larga escala, destinando sua produç o para o mercado externo. Dentre os produtos que o governo buscava exportar tinham destaque a madeira, a carne bovina e os minerais.

Dessa forma, no governo do general Geisel, as iniciativas de colonizaç o dirigida foram abandonadas, ficando mais evidente que as pol ticas de intervenç o do governo federal estavam, inquestionavelmente, articuladas com a necessidade do fortalecimento e com a implantaç o, em termos regionais, de projetos mobilizadores de grandes quantidades de capitais. Em outras palavras, a força social capaz de dinamizar a economia regional era atribu da ent o grande empresa. Anunciava-se na poca que "o quarto governo da Revoluç o convoca o empres rio para essa nova cruzada - ocupar economicamente a Amaz nia e corrigir as defici ncias da colonizaç o dirigida" (BITTENCOURT, 1974, p. 34).

A postura pol tica de atrair o empresariado de fora para a regi o carreou, assim, um volume maior de recursos oriundos do fundo $\mathrm{p}$ blico para atrair grandes capitais para a regi o. Inclusive parcela dos recursos que foi destinada colonizaç o dirigida passou, em 1974, a ser direcionada para reas e atividades capazes de atrair grandes capitais para a regi 0.

Naquele contexto, o governo federal criou, em 1974, o Programa de $\mathrm{P}$ los Agropecu rios e Agrominerais da Amaz nia (Polamaz nia). Uma pol tica inspirada por uma noç o te rica que preconizava que o melhor caminho para se desenvolver regi es "atrasadas" seria atrav s de um desenvolvimento que deveria se processar de forma polarizada (HIRSCHMAN, 1961; PERROUX, 1967). Os planos federais previam a 
implantaç o de 15 "p los de crescimento", na Amaz nia brasileira, dentre os quais o de Caraj s (vinculado exploraç o do ferro) e o de Trombetas (associado extraç o da bauxita) (Figura 2). Visando aumentar as exportaç es de recursos naturais por meio da ampliaç o das "vantagens comparativas", foram criadas novas infra- estruturas no campo da energia, da comunicaç o e dos transportes. 0 governo federal ainda redirecionou mecanismos de pol tica de incentivos fiscais para reas geogr ficas dos $\mathrm{p}$ los, com a finalidade de propiciar investimentos massivos e espacialmente concentrados. Para isso, o Estado ancorava-se em uma vis o de fronteira de recursos, de planejamento e de normalizaç o do desenvolvimento regional que tinha por fundamento estrat gico a concentraç o espacial de capitais nos p los indicados pelo Governo. A decis o de impulsionar um processo de desenvolvimento por meio de uma cadeia de ligaç es para frente e para tr s das atividades consideradas "chave" produziu, no entanto, efeitos limitados na diversificaç o da produç o regional/local.

A 1 gica que orientou a pol tica de modernizaç o regional, materializada pela intervenç o promotora da modernizaç o da Amaz nia com base nos grandes investimentos empresariais, voltou-se, ent o, decisivamente para a implantaç o regional de atividades agropecu rias, extrativistas e industriais que gerassem divisas necess rias ao pagamento da d vida externa brasileira.

\section{7 - AS POLÍTICAS DA UNIÃ O, O DESENVOLVIMENTO DA PECUÁRIA, DO EXTRATIVISMO MADEIREIRO E A LUTA PELA TERRA}

No in cio da d cada de 70, embora o PROTERRA previsse, de fato, a redistribuiç o de terras devolutas, seu maior objetivo parece ter sido promover a agropecu ria e criar uma nova classe de fazendeiros "modernos" de pequeno e $m$ dio porte, a fim de substituir a agricultura de subsist ncia (HALL, 1989, p. 30). Entre 1975 e 1979, a venda de terra do INCRA para empresas e grandes fazendeiros foi efetuada em reas originalmente destinadas aos migrantes (HALL, 1989, p.39). Se, de um lado, as grandes propriedades cresciam em reas, de outro lado, no estado do Par , de 1960 a 1996 , os pequenos propriet rios com menos de 100 hectares triplicavam em n mero (Quadro 2).

$\mathrm{H}$ uma correlaç o grande entre crescimento das reas de pastagens e da exploraç o madeireira. A opç o pelo amplo favorecimento 


\begin{tabular}{|c|c|c|c|c|c|c|c|c|c|c|}
\hline \multicolumn{11}{|c|}{ Dimensão da propriedade fundiária (hectares) } \\
\hline \multirow{2}{*}{$\begin{array}{c}\begin{array}{c}\text { Extrato } \\
\text { de área }\end{array} \\
\text { Ano }\end{array}$} & \multicolumn{2}{|c|}{$0<10$} & \multicolumn{2}{|c|}{$10<100$} & \multicolumn{2}{|c|}{$100<1000$} & \multicolumn{2}{|c|}{$1000<10000$} & \multicolumn{2}{|c|}{+10000} \\
\hline & $\begin{array}{l}\text { \% em } \\
\text { relação à } \\
\text { área total }\end{array}$ & $\begin{array}{l}\% \text { em } \\
\text { relação ac } \\
\text { n. }{ }^{\circ}\end{array}$ & $\begin{array}{l}\text { \% em } \\
\text { relação à } \\
\text { área }\end{array}$ & $\begin{array}{c}\% \text { em } \\
\text { relação ao } \\
\text { n. }\end{array}$ & $\begin{array}{l}\% \text { em } \\
\text { relação à } \\
\text { área }\end{array}$ & $\begin{array}{c}\% \text { em } \\
\text { relação ao } \\
\text { n. }\end{array}$ & $\begin{array}{c}\% \text { em } \\
\text { relação à } \\
\text { área total }\end{array}$ & $\begin{array}{c}\% \text { em } \\
\text { relação ao } \\
\text { n.o }\end{array}$ & $\begin{array}{c}\% \text { em } \\
\text { relação à } \\
\text { área total }\end{array}$ & $\begin{array}{c}\% \text { em } \\
\text { relação ao } \\
\text { n. }{ }^{\text {o }}\end{array} \mid$ \\
\hline 1960 & 2,5 & 41,8 & 23,0 & 46,9 & 28,0 & 6,9 & 28,0 & 0,6 & 18,5 & 0,03 \\
\hline 1970 & 2,1 & 48,05 & 19,7 & 45,2 & 15,3 & 4,7 & 30,3 & 0,8 & 32,6 & 0,05 \\
\hline 1980 & 1,5 & 36,2 & 19,1 & 51,3 & 22,0 & 11,5 & 22,0 & 0,7 & 35,4 & 0,1 \\
\hline 1985 & 1,3 & 32,7 & 19,4 & 51,8 & 26,7 & 14,3 & 23,0 & 0,9 & 29,6 & 0,1 \\
\hline 1996 & 0,9 & 31,5 & 18,3 & 50,7 & 29,9 & 16,7 & 27,0 & 1,1 & 23,9 & 0,0 \\
\hline
\end{tabular}

Quadro 2: Números dos estabelecimentos rurais por dimensão de área.

Fonte: Censos agropecuários, IBGE. 


\section{8 - AS POLÍTICAS DA UNIÃO VOLTADAS PARA G ARANTIR A AM- PLIAÇÃO DAS ATIVIDADES DE EXTRAÇÃ 0 E TRANSFORMA- ÇÃ O MINERAL}

Os problemas derivados da modernizaç o do espaço agr rio regional por meio do incentivo grande pecu ria, o agravamento da crise econ mico-financeira, a ampliaç o exponencial dos serviços da d vida, a deterioraç o das condiç es da balança de pagamentos nacional, conduziram o governo federal a desenvolver aç es visando ampliar as exportaç es brasileiras de mat rias-primas, ganhando nfase, ainda maior, a A maz nia oriental brasileira. Para isto, o governo buscou edificar o mais $r$ pido poss vel as infra-estruturas capazes de viabilizar os processos de valorizaç o dos recursos minerais existentes na regi 0.

No final da d cada de 1970, o governo federal, para viabilizar a implantaç o dos empreendimentos voltados produç o da alumina e do alum nio prim rio, decidiu arcar sozinho com os custos referentes construç o da usina hidrel trica de Tucuru (Figura 5) epatrocinou ainda a infra- estrutura urbana e portu ria necess ria ao funcionamento das ind strias de transformaç o mineral, a Albras e a Alunorte, em Barcarena (PA); e a Alumar em S o Lu s, (MA).

Incentivada e apoiada pelo governo brasileiro, a Companhia Vale do Rio Doce - CVRD - poca uma empresa estatal de capital misto que assistia reduç o do estoque do ferro na regi o Sudeste do pa s - decidiu explorar minas de ferro e mangan s da Serra de Caraj s, no sudeste do Par . Embora pesquisas j estivessem sendo realizadas desde o final da d cada de 1960, a CRVRD deu in cio em 1980 implantaç o do Projeto Ferro Caraj s, um complexo minaferrovia- porto, destinado a explorar o min rio de ferro de alto teor da Serra dos Caraj s. Neste mesmo ano, o governo federal lançou o Programa Grande Caraj s - PGC, um projeto de desenvolvimento para a Amaz nia oriental, tendo como eixo principal a edificaç o de infra-estrutura e a atraç o de investimentos para a rea do corredor formado pela Estrada de Ferro Caraj s - EFC, que liga a mina em Caraj s ao porto de Itaqui-Madeira, em S o Lu s do Maranh o.

0 Programa $G$ rande $C$ araj s (Figura 5) constituiu- se uma tentativa de o governo coordenar a execuç o, de forma mais gil, de projetos $\mathrm{j}$ existentes na rea e de estimular a modernizaç o da regi o. 0 PGC passou, ent $\mathrm{o}$, a receber aporte de mais de $1 / 4$ dos fundos $\mathrm{p}$ blicos destinados a todo o Polamaz nia, a contar com um sistema especial de financiamento estatal, a envolver negociaç es de cr ditos com o sistema financeiro internacional, al $\mathrm{m}$ de ter sido beneficiada com a criaç o de um sistema adicional de isenç es fiscais, administrado pela SUDAM e BASA. 


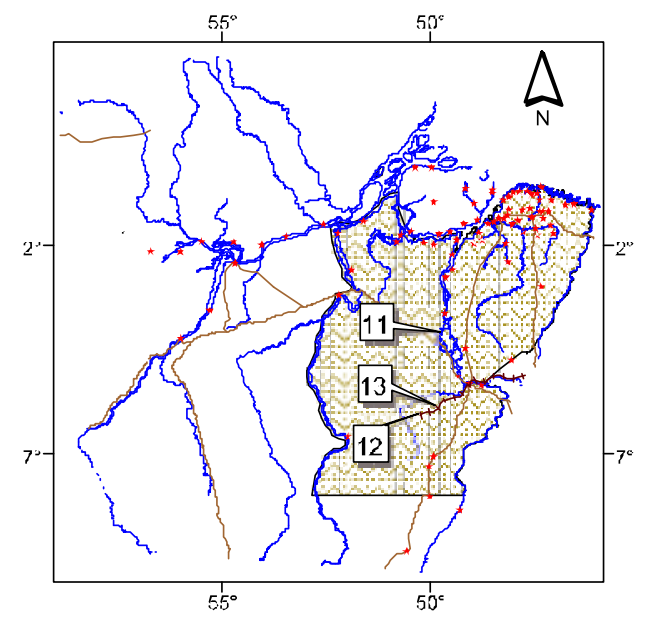

PROGRAMA GRANDE CARAJÁS: "integraçåa

espacial do desenvalvimento"e maior concentraçāo espacial de incentivos fiscais(1981-1990)

Programa Grande Carajás

11 l agu de Tucuruí

12 Minas CVRD (ferro, ouro, manganês)

13 Fstrada de Ferro da Carajás

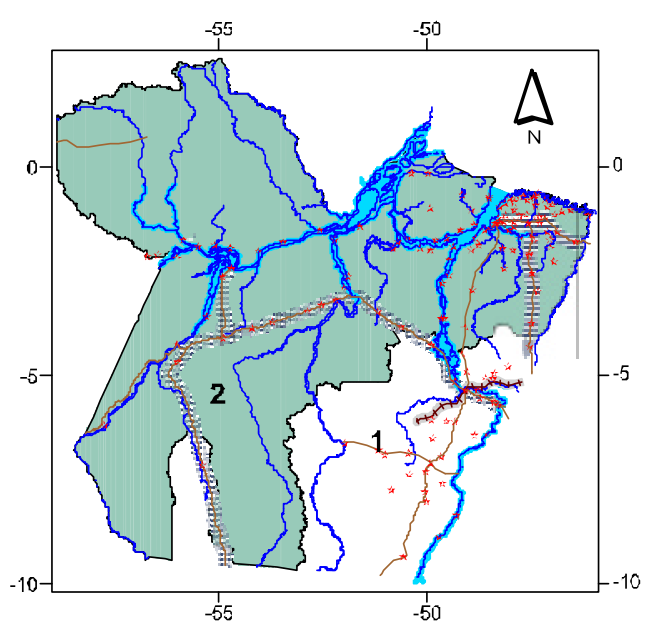

Eixos estruturadores do desenvolvimento: enfase no acesso a mercados por meio de eficiência crescente da infra-estrutura (1996-2003)

Eixos de integração nacional e áreas de influência

$\square$ Araguaia-Tocantins (1)

Dadeira-Amazonas (2)

Eixo hidrográfico

$\square$ Eixo ferroviário

Eixo rodoviário

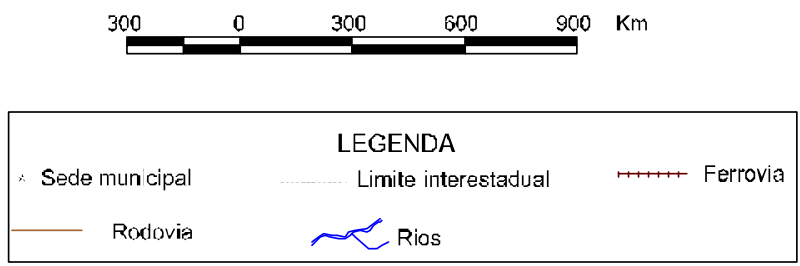

Figura 5: Elementos da reconfiguraç o espacial na Amaz nia oriental (1985 - 2003).

Fontes: BRASIL (1 973); Ferreira Filho (1 965); IBGE (1 984); IRDA; IBGE (1 966); MARANH ÃO (2000); Martinelo (1 985); Mendes (1 971); SUDAM (1 976); Valverde e Dias (1 967); A map , 2000. 
Para garantir a implantaç o dos projetos m nero- metal rgicos centrais ao $\mathrm{PGC}$, al $\mathrm{m}$ da necess ria mobilizaç o dos vultosos recursos, foi preciso estabelecer o controle sobre mais de um milh o de hectares de terras (ALMEID A, 1994, p.103), parte delas destinadas aos Projetos da CVRD e seus parceiros, como as guseiras, e outra parcela destinada construç o da hidrel trica de Tucuru, cujo lago inundou mais de $2.430 \mathrm{~km}$ de terras (Eletronorte, 198a, p. 6). Para o controle de faixas descomunais de terras, foi decisiva a atuaç o do Grupo Executivo de Terras do Araguaia Tocantins (GETAT), que estabeleceu uma pol tica fundi ria prevendo o assentamento de ocupantes de terras no mbito do Programa em $n$ mero aqu $m$ das necessidades geradas pelo intenso fluxo migrat rio que se dirigiu para a regi 0.

Al $\mathrm{m}$ dos incentivos fiscais concedidos em $\mathrm{n}$ vel federal, em conson ncia com o modelo de desenvolvimento industrial do Polamaz nia, as empresas atra das para a regi o contaram com as pol ticas de ren ncia fiscal adotadas pelos estados federados visando auxiliar a instalaç o local de empresas e promover a verticalizaç o e a diversificaç o da produç o industrial, repetindo a estrat gia federal de criar infra- estrutura b sica e de isentar as empresas do pagamento dos impostos.

\section{9 - A CRISE FINANCEIRA, A LIMITADA CAPACIDADE DE INTERVENÇÃO DA UNIÃO E AS MUDANÇAS CONSTITUCIONAIS NOS ANOS 80}

0 poder de centralizaç o autorit ria dos governos militares foi sendo corro do no decorrer da d cada de 1980. Mesmo assim, no fim dos governos militares, em 1 985, foi lançado o Projeto Calha Norte, um plano de ocupaç o sistem tica de reas estrat gicas correspondentes $\mathrm{s}$ calhas norte dos rios Solim es e Amazonas. $\mathrm{N}$ o se restringindo $\mathrm{s}$ calhas dos principais rios, a rea de atuaç o do projeto foi definida como a faixa fronteiriça que vai de Tabatinga (fronteira com o Peru), na A maz nia 0 cidental, a Oiapoque (fronteira com as $\mathrm{G}$ uianas), na A maz nia oriental.

No in cio dos anos $90 \mathrm{j}$ era evidente a frustraç o das prediç es relacionadas ao surgimento na regi o do programa de uma rede de relaç es mercantis e $n$ o mercantis decorrentes da m nero-metalurgia e capazes de impulsionar o desenvolvimento regional. Assim, o PGC, que $\mathrm{j}$ vinha sofrendo questionamentos de parcela da sociedade, foi esvaziado para, em seguida, ser extinto em 1991. A Sudam, como 
Maur lio de Abreu Monteiro / Maria C lia Nunes Coelho

diversos outros $\mathrm{rg}$ os da burocracia federal que tiveram papel de destaque no aporte estatal implantaç o regional de empresas $\mathrm{m}$ nerometal rgicas, teve a sua import ncia reduzida, uma vez que parcela do sistema de ren ncia fiscal que era executado no mbito do PGC tinha sido extinta. É bem verdade que instrumentos que tiveram import ncia na execuç o das pol ticas dos militares, como o fINAM ou como a concess o de isenç o de IR, foram mantidos e passaram a ser coordenados pela Sudam.

0 fim dos governos militares e a promulgaç o da Constituiç o de 1988 proporcionaram importantes mudanças que alteraram as relaç es entre munic pios, estados e Uni o, implicando alteraç o na conduç o das pol ticas de desenvolvimento da A maz nia.

\section{0 - REFORMAS NO ESTADO E EIXOS DE INTEGRAÇÃO}

A eleiç o de Fernando Collor Presid ncia da Rep blica, em 1989 , e a de Fernando Henrique Cardoso, em 1993, consolidaram alteraç es em aspectos relevantes da forma de atuaç o do Estado, do sentido e das funç es da intervenç o estatal. Tais mudanças eram derivadas, sobretudo, de din micas mundiais que impuseram novos modelos de desenvolvimento para as economias nacionais. $G$ anhou força crescente na agenda do governo brasileiro a necessidade de "liberalizaç o da economia", realizaç o de "ajustes" capazes de "ampliar e adaptar a competitividade das economias nacionais" diante do "imperativo" de um mundo cada vez mais "globalizado". No bojo de tais ajustes, inclu ram-se a diminuiç o de barreiras alfandeg rias, a retraç o da tributaç o e a reduç o da participaç o estatal na economia, por via de privatizaç es de empresas estatais, como veio a acontecer com a CVRD.

Houve, assim, uma alteraç o dos discursos oficiais. A firmava-se que havia se configurado no plano mundial um novo paradigma de desenvolvimento, cuja faceta mais evidente a globalizaç o, evidenciada por uma crescente interpenetraç o dos mercados de bens e serviços de diferentes pa ses, por uma nova vis o de competitividade em $\mathrm{n}$ vel mundial e por um extraordin rio aumento da dimens o e velocidade dos fluxos financeiros nos mercados internacionais de capitais (Brasil, 1997, p. 23). Assim, as formas de atuaç o estatal passaram a ser norteadas por indicaç es te ricas que preconizavam a necessidade da dr stica reduç o da intervenç o estatal na economia.

0 correram, ent $\mathrm{o}$, mudanças nas pol ticas $\mathrm{p}$ blicas que favoreceram, em termos nacionais, aç es direcionadas a reduzir a presença do Estado no desenvolvimento das atividades infra- estruturais 
e produtivas, al $\mathrm{m}$ de restringir a aç o tutelar que este exerceu sobre tais iniciativas durante tantos anos. Essa posiç o pol tica foi reforçada, na d cada de 90, pela crise fiscal que atingiu a Uni o Federal e estados membros da federaç o Naquele contexto, os planejadores estatais passaram a implementar pol ticas $\mathrm{p}$ blicas derivadas da vis o de que era imperioso "o crescimento da responsabilidade da iniciativa privada no processo de desenvolvimento econ mico" (Brasil, 1997, p.13).

Segundo o discurso oficial, este novo cen rio tamb $\mathrm{m}$ foi marcado pela "reaç o contra o Estado intervencionista e providencial", pela "redescoberta das virtudes da economia de mercado" e pelo "relativo sucesso de programas de reestruturaç o, abertura, liberalizaç o e estabilizaç o econ mica” (Brasil, 1997, p. 26). De tal processo resultaria, tamb $\mathrm{m}$, uma forte liberalizaç o da economia, envolvendo a reduç o da proteç o aduaneira e a maior integraç o econ mica com o exterior (Brasil, 1997: 28). Portanto, as aç es e as pol ticas federais passaram a articularse em torno de um discurso que preconizava como indispens veis desestatizaç o os seguintes itens: a privatizaç o e o fortalecimento da aç o reguladora do Estado; a descentralizaç o e a melhoria do planejamento, da coordenaç o e dos n veis de produtividade; a efici ncia na implementaç o de pol ticas governamentais; e a elevaç o dos padr es de qualidade e de gest o dos serviços p blicos (Brasil, 1997, p. 33).

É o cen rio tamb $\mathrm{m}$ no qual mudaram as estrat gias em relaç o s concepç es de desenvolvimento regional, que passam agora a se ancorar em noç es como as de "eixos de integraç o nacional e internacional", tendo por base vias de transporte de longa dist ncia que possibilitariam " acesso a mercados e melhorar a capacidade competitiva dos sistemas econ micos regionais" (Brasil, 1997, p. 17).

0 planejamento estatal passa ent o a reconsiderar a implantaç o e consolidaç o de uma eficiente infra- estrutura f sica como um dos mais importantes requisitos para as tentativas de integraç o e desenvolvimento econ mico da regi o Norte (Brasil, 1997, p. 41) com outras regi es, dentro e fora do Brasil, por meio de um esquema de log stica integrada, envolvendo a articulaç o e a integraç o de redes modernas de comunicaç es, transportes e energia, seja num sentido norte-sul, atrav s de corredores multimodais, como aqueles que incorporam o rio Madeira, o A raguaia-Tocantins, a ferrovia Norte-Sul e a ferrovia de Caraj s, seja na vertente leste-oeste, mediante o aproveitamento da moderna infra-estrutura portu ria de Barcarena, Itaqui, Pec m e Suape (Brasil, 1997, p. 31) (Figura 5).

As estrat gias de integraç o e desenvolvimento contidas no Programa Brasil em Aç o (1 996-1 999) e no Avança Brasil (2000-2003) 
Maur lio de Abreu Monteiro / Maria C lia Nunes Coelho

se vinculam noç o de que a reduç o do custo de transporte reflete direta e decisivamente sobre os custos de exportaç o ou de importaç o de mercadorias, colaborando para melhorar, assim, na vis o dos planejadores brasileiros, a capacidade competitiva dos sistemas econ micos regionais. A o que se somou a preconizaç o da necessidade de se reduzir ao $\mathrm{m}$ ximo os impostos, em especial os incidentes sobre produtos destinados exportaç o como elemento de reduç o de custos e de ampliaç o da competitividade dos produtos regionais. Um opç o estrat gica que se materializou em medidas como a Lei Complementar $n^{0} 87 / 96$, que ficou tamb $m$ conhecida como Lei Kandir. Esta Lei isenta de recolhimento do Imposto sobre Circulaç o de Mercadorias e Serviços - ICMS os produtos prim rios ou semibeneficiados voltados para a exportaç o. A Lei Kandir, todavia, afeta as finanças, particularmente dos estados exportadores de mat rias- primas. Com as eleiç es de 2002 , a mudança de governo, e a posse do presidente Lu s In cio Lula da Silva, esta postura $n$ o foi substancialmente alterada, passando inclusive a ser defendida a necessidade da constitucionalizaç o deste princ pio, que, do ponto de vista tribut rio, prejudica os estados exportadores, como o caso do Par.

\section{1 - VALORIZAÇÃO DE NOVOS RECURSOS E NOVOS ELEMENTOS NA POLÍTICA PARA A AMAZÔNIA}

A preocupaç o com a defesa da Amaz nia e com sua proteç o ambiental levou o governo brasileiro a lançar o Projeto do Sistema de Vigil ncia da Amaz nia (SIVAM) e o Projeto do Sistema de Defesa da A maz nia (SIPAM) na d cada de 1990. A pol mica suscitada, entre outras coisas, pela natureza de tais projetos fez com que as metas de combate ao tr fico de drogas e de monitoramento das condiç es ambientais tivessem import ncia ampliada no contexto deste projeto.

A preocupaç o internacional com a import ncia da floresta amaz nica para o clima do planeta e para a preservaç o das riquezas associadas aos recursos gen ticos, aos recursos h dricos e biodiversidade, de um lado, o crescimento dos movimentos ambientais, a atuaç o local das 0 rganizaç es $\mathrm{N}$ o- $\mathrm{G}$ overnamentais e os avanços no campo das cooperaç es internacionais, de outro, $\mathrm{v} \mathrm{m}$ redefinindo as pol ticas ambientais para a Amaz nia. No caso das cooperaç es internacionais, ressalta-se a import ncia do Programa Piloto para a Proteç o das Florestas Tropicais do Brasil - PPG 7 - fundado pelo Rainforest Trust Fund e financiado pelo governo alem o, pelo Banco 
Mundial e pela United Nations Environment Program (UNEP). Este projeto fruto de uma associaç o entre o governo brasileiro, a sociedade civil e a comunidade internacional objetivando a conservaç $\mathrm{o}$ das florestas tropicais e o desenvolvimento sustent vel.

Os esforços para implementaç o de pol ticas voltadas delimitaç o de terras ind genas, vista como forma de preservaç o da floresta, e a criaç o de unidades de conservaç o ambiental implicaram mudanças significativas, $\mathrm{n}$ o imagin veis no Brasil de 30 anos atr s. As terras ind genas existentes na Amaz nia Legal correspondiam a uma rea de 103.396.426 ha, ou seja, a 20,66\% do total da regi o, em novembro de 2001, existiam 171 Unidades de Conservaç o na Amaz nia legal que representam a uma rea de 64.586.259 ha, segundo dados obtidos nos instrumentos legais de criaç o, ou seja, $12,9 \%$ da rea total da Amaz nia Legal (RICARDO e CAPOBIANCO, 2001, p. 246). Al m de novas unidades de conservaç o e da demarcaç o das terras ind genas, existem ainda os experimentos associados bio-sociodiversidade e aos Projetos Pilotos para Gest o Ambiental Integrada nos estados (BECKER, 2001).

\section{2 - PASSAD0, PRESENTE E FUTURO}

De 1923 a 1940, as tentativas esparsas de promover a economia amaz nica tiveram resultados pouco efetivos. Per odo no qual, o crescimento populacional foi tamb m pouco significativo, em contraste com o crescimento demogr fico surpreendente do per odo ureo da economia da borracha (1 865 a 1912 ).

Entre 1950 e 1980, as migraç es de outras regi es para a A maz nia foram intensas. 0s saldos migrat rios nas d cadas de $1970 \mathrm{e}$ 1980 para a regi o Norte foram de 798.478 e 1.376.341, respectivamente. No entanto, esses saldos contribu ram menos que o crescimento vegetativo para o crescimento total, representando apenas $35,1 \%$ e $41,1 \%$ do crescimento total da populaç o nos respectivos per odos intercensit rios (SAWYER, 1995, p.74).

As aberturas de estradas marcaram o in cio de uma nova trajet ria na hist ria da Amaz nia, entretanto, foi a pol tica do Polamaz nia que redefiniu a configuraç o de uma nova organizaç o da regi o. $\mathrm{N}$ o h registro na hist ria regional recente de uma outra ruptura ou ponto de inflex o t o profundo que tenha sido intimamente relacionado com as pol ticas $\mathrm{p}$ blicas traçadas segundo olhares de fora da regi o. A A maz nia oriental e particularmente o estado do Par s o hoje, sem d vida, reveladores da combinaç o das pol ticas que sucederam a 
criaç o de p los. A edificaç o de infra-estrutura de energia, transporte e de comunicaç es, as pol ticas de ren ncia fiscal e os aportes credit cios vinculados implementaç o de projetos agropecu rios, madeireiros e de extraç o e transformaç o mineral de grande porte derivadas das estrat gias de $\mathrm{p}$ los de desenvolvimento na d cada de 70 foram fundamentais para a diferenciaç o da din mica regional e urbana, para a reestruturaç o demogr fica (verificada por meio do crescimento populacional e pelo surgimento de novos munic pios), como tamb $\mathrm{m}$ para a reestruturaç o econ mica regional/ocal. A populaç o cresceu, intensificou-se a mobilidade populacional na regi o. Neste quadro, o estado do Par (Gr fico 2) vem apresentando o maior contingente populacional da regi o norte.

Nos anos 90, tornou-se mais evidente a mobilizaç o alguns seguimentos da sociedade, em especial aqueles dispensados pelas empresas construtoras contratadas para a implantaç o de grandes dos projetos industriais e infra-estruturais, os que emergem em busca de outras atividades como decorr ncia da reduç o da atividade garimpeira, exclu dos da terra e dos empregos formais, aos quais se somam antigos posseiros e sem-terra, estes ltimos organizados, em grande medida. $\mathrm{S}$ o atores sociais que $\mathrm{v} \mathrm{m}$ contribuindo para mudar a estrutura fundi ria no sudeste do Par . Mudança, por $\mathrm{m}$, que $\mathrm{t} \mathrm{m}$ sido marcada por grande viol ncia.

Todavia, a crise financeira que provocou uma reduç o nos investimentos regionais contribuiu para a reduç o da migraç o interregional para a Amaz nia. No per odo de 1986-1991, o saldo migrat rio da regi o Norte foi de apenas 131.218 , caindo para 60.844 no per odo de 1991-1996. Atualmente, h grande mobilidade populacional dentro da regi o. A mobilidade tempor ria foi facilitada pelas melhorias nos sistemas de transporte. A migraç o inter-regional se d nos sentidos leste- oeste, tomando os rumos principalmente de Roraima, norte do Mato Grosso e sul do estado do Amazonas. O volume de migraç o intraestadual na regi o foi de 708.274 entre 1986 e 1991 e de 619.991 entre 1991 e 1996 (ABEP, 1998).

Os planos do Estado nacional brasileiro, "Brasil em Aç o" (19961999) e "Avança Brasil" (2000-2003) cujos fundamentos n o foram reformulados no governo do Presidente Lula da Silva e que continuou recorrendo ao discurso da necessidade da criaç o de eixos estruturadores de desenvolvimento regional. Renova-se, assim, o debate sobre a capacidade de investimentos infra-estruturais provocarem dinamismo regional ou gerarem novos desequil brios entre munic pios e regi es. Questiona-se a capacidade de reverter tend ncias delet rias 
derivadas de planos anteriores e de se criar solidariedade regional entre munic pios, a partir de din micas ligadas ao mercado, tais como a ampliaç o da circulaç o de mercadorias por vias de transporte como a Estrada de Ferro Caraj s, a hidrovia Araguaia-Tocantins, ou mesmo aquelas de car ter multimodal.

Assim, pode-se afirmar que, nos ltimos trinta anos, os dois grupos de estrat gias de modernizaç o regional marcaram e marcam a hist ria recente do Par mais do que qualquer outro da Amaz nia. Enquanto um deles consistiu nas tentativas de estabelecimento de $\mathrm{p}$ los de crescimento econ mico e de complexos industriais motrizes, o outro diz respeito aos esforços de estimular eixos estruturadores de desenvolvimento regional. Ambos baseiam-se em supostos te ricos distintos. No primeiro grupo de estrat gias, julga-se ser necess ria a participaç o estatal para contrabalançar din micas produzidas pelo mercado, considerando que a modernizaç o de certas regi es n o ocorreria sem a aç o do Estado. $\mathrm{J}$ o segundo grupo integra estrat gias de desenvolvimento regional baseadas no suposto da efic cia das din micas de mercado. Ambas representam estrat gias de modernizaç o que privilegiam o velho conceito das "vantagens comparativas" e que, conseq entemente, tendem a ser espacialmente seletivas e, portanto, concentradoras de mudanças sociais; no primeiro caso, em torno de um p lo, de um complexo industrial e, no segundo, ao longo de um eixo. Tais estrat gias atra ram e atraem capitais e fluxos migrat rios intensos, desencadeando impactos sobre o crescimento e mobilidade populacional e impondo novos processos de mudança territorial, social, econ mica e ambiental em vastas reas do estado do Par . 


\section{REFERÊNCIAS}

ABEP. Gente em movimento: um retrato da migraç o no Brasil. $S$ o Paulo: Associaç o Brasileira de Estudos Populacionais, 1998.

ALMEIDA, A. W. B. de. Caraj s: a guerra dos mapas. Bel m: Fal ngola, 1994. 329p.

AMAPÁ. Zoneamento Ecol gico Econ mico do Sul do Estado do A map . Corrdenaç o de Benedito Rabelo. Macap : IEPA, 2000, 44p.

BECKER, B. S ntese do Processo de Ocupaç o da Amaz nia - Liç es do Passado e do Presente. In: MMA (Org.). Causas e Din mica do Desmatamento na Amaz nia. Bras lia, MMA.,2001, pp. 73-90.

BITTENCOURT, Luis Carlos. Polamaz nia. Empres rios e n o colonos. Revista com rcio e mercados. Ano VIII, n 87, novembro de 1974.

BRASIL. Plano Nacional de Viaç o. Rio de Janeiro CNT, 1973, 51p.

BRASIL. Minist rio do Planejamento e Orçamento. Indicaç es para uma nova estrat gia de desenvolvimento regional. Bras lia: Universa, 1997.

BRASIL. Comiss o Executiva da Rodovia Bel m - Bras lia. Rodovia Bel m - Bras lia; a rodovia da unidade e suas implicaç es de ordem t cnica, econ mica e pol tica / Comiss o Executiva da Rodovia Bel m Bras lia. Bel m: H. Barra, 1960. 65p.

CORREA, L. M A Borracha da A maz nia e a II Guerra Mundial. Manaus: Governo do Estado do Amazonas, 1967. 126p.ELETRONORTE. Relat rio diagn stico: reservat rio da usina hidrel trica de Tucuru. Bras lia, v.1. (Revis o 1), 1984.

FERREIRA FILHO, C. Por que perdemos a Batalha da Borracha. Manaus: Ediç es do Estado do Amazonas. S rie Euclides da Cunha, 1965. 373 p. 
HALL, A. A maz nia: Desenvolvimento para Quem? Rio de Janeiro, Jorge Zahar Editor, 1989.

HIRSCHMAN, Albert O. Estrat gia do desenvolvimento econ mico. Rio de Janeiro: Fundo de Cultura, 1961.

HURTIENNE, T. Agricultura familiar e desenvolvimento rural sustent vel. In: COELHO et al. (orgs.) Estado e pol ticas p blicas na Amaz nia: gest o do desenvolvimento regional. Bel m, CEJUP, 2001.

IBGE. Atlas do Maranh o. Rio de Janeiro, 1984. 104 p. Escalas variam.

IBGE. Censo Demogr fico de 1991. Dispon vel em: < http:// www.ibge.gov.br> . Acesso em: 15/03/2004

IBGE. Censo Demogr fico de 1996. Dispon vel em: < http:// www.ibge.gov.br> . Acesso em: 15/03/2004

IBGE. Censo Agropecu rio do Par (1995/96). Rio de Janeiro, 1998.

MACHADO, L. O. O Controle Intermitente do Territ rio Amaz nico. In: Territ rio, No. 2, Vol. 1, 1997, pp. 19-32.

MAHAR, Dennis. J. Desenvolvimento econ mico da Amaz nia: uma an lise das pol ticas governamentais. Rio de Janeiro: IPEA/NPES. (Relat rio de Pesquisa, 39), 1978.

MARTINELO, Pedro. A “Batalha da borracha” na Segunda Guerra Mundial e suas conseq ncias para o vale amaz nico. S o Paulo (Tese de doutorada - Hist ria Econ mica USP), 1985. 368p.

MENDES, Armando. Estrada para o Desenvolvimento. Bel m-Par : IDESP, 1971. 243p.

MYRDAL, Gunnar. Teoria econ mica e regi es subdesenvolvidas. Rio de Janeiro: Saga, 1968.

OLIVEIRA, Francisco de. Elegia para uma re(li)gi o: SUDENE, nordeste. Planejamento e conflito de classes. Rio de Janeiro: Paz e Terra, 1972.

- - - - A reconquista da Amaz nia. In: D' INCAO, Maria Angela, SILVEIRA, Isolda Maciel (Orgs.). A A maz nia e a crise de modernizaç o. Bel m: Museu Paraense Em lio Goeldi, 1994. pp. 185-96. 
Maur lio de Abreu Monteiro / Maria C lia Nunes Coelho

PERROUX, François. Os p los de crescimento. In: A economia do s culo XX, Lisboa: Livraria Morais, 1967.

PNUD/PEA A tlas de desenvolvimento humano no Brasil. Rio de Janeiro: PNUD/PEA/FJP, 1997.

RICARDO, F;CAPOBIANCO, J.P. Unidades de conservaç o na amz nia legal. In: CAPOBIANCO, J.P. Biodiversidade na Amaz nia brasileira: Avaliaç o e aç es priorit rias para a conservaç o, uso sustent vel e repartiç o de benef cios.S o Paulo: Institutosocioambiental, 2001.

SAWYER, D. Fecundidade e mortalidade na Amaz nia: notas sobre as estimativas e interpretaç es. In: Encontro Nacional de Estudos Populacionais, 2, Águas de S o Pedro. 1980. pp. 113-83.

- - - - Evoluç o demogr fica, qualidade de vida e desmatamento na Amaz nia. In: MMA (Org.) Causas e Din mica do Desenvolvimento na A maz nia. Bras lia: MMA. 2001. pp. 73-90.

SPVEA. Pol tica de Desenvolvimento da Amaz nia (1 954-1 960). Rio de Janeiro, 1960. 210p.

SUDAM Plano de desenvolvimento da Amaz nia (1 972-1 974). Bel m, 1971.

SUDAM II Plano Nacional de Desenvolvimento; Programa de aç o do Governo para a Amaz nia. Bel m, 1976. 100p.

VALVERDE, Orlando; DIAS, Catharina Vergolino. A Rodovia Bel m- Bras lia. Rio de Janeiro: Fundaç o IBGE, 1967. 350p.

VERÍSSIMO, A. et al. O Diagn stico do Uso da Terra na Amaz nia: Exploraç o Madeireira, Agricultura e Agropecu ria. In: CAPOBIANCO, J. P. et al. (Orgs) Biodiversidade na A maz nia Brasileira. S o Paulo, Est. Liberdade, 2001, pp. 327-347.

WEINSTEIN, B. A Borracha na Amaz nia: Expans o e Decad ncia 1 850-1 920. S o Paulo, Hucitec, 1993.

Texto submetido Revista em 14.03.2004 e aceito para publicaç o em 11.05.2004. 